\title{
Acute Ischemic Stroke and Convexity Subarachnoid Hemorrhage in Large Vessel Atherosclerotic Stenosis: Case Series and Review of the Literature
}

\author{
Abeer Safan ${ }^{1}$, Naveed Akhtar ${ }^{1}$, Saadat Kamran ${ }^{1}$, Dr. Yahia Imam ${ }^{1}$, Haya Al-Taweel ${ }^{2}$, \\ Ayman Quateen $^{1}$, Ayman Zakaria ${ }^{1}$, and Ahmed own ${ }^{1}$ \\ ${ }^{1}$ Hamad Medical Corporation \\ ${ }^{2}$ Weill Cornell Medicine - Qatar
}

February 20, 2022

\begin{abstract}
Atraumatic convexity subarachnoid hemorrhage (cSAH) is a rare non-aneurysmal SAH, commonly due to ipsilateral internal carotid artery (ICA) stenosis. It is unusual for the cSAH to occur contralaterally to the infarct. We report two cases of acute ischemic stroke associated with contralateral and ipsilateral cSAH that had different presentations.
\end{abstract}

\section{Hosted file}

Acute ishcemic stroke cSAH final edit-W.docx available at https://authorea.com/users/383880/ articles/557141-acute-ischemic-stroke-and-convexity-subarachnoid-hemorrhage-in-largevessel-atherosclerotic-stenosis-case-series-and-review-of-the-literature

\section{Hosted file}

cSAHLRtable.docx available at https://authorea.com/users/383880/articles/557141-acuteischemic-stroke-and-convexity-subarachnoid-hemorrhage-in-large-vessel-atheroscleroticstenosis-case-series-and-review-of-the-literature

\section{Hosted file}

Figures cSAH.pdf available at https://authorea.com/users/383880/articles/557141-acuteischemic-stroke-and-convexity-subarachnoid-hemorrhage-in-large-vessel-atheroscleroticstenosis-case-series-and-review-of-the-literature 